\title{
Tropical Cyclones: Meteorological Aspects
}

\author{
Mark A. Lander ${ }^{1}$ \\ Water and Environmental Research Institute of the Western Pacific, University of Guam, UOG Station, Mangilao, \\ Guam (USA) 96923
}

Sailors have long recognized the existence of deadly storms in tropical latitudes where the weather was usually a mix of bright sun and gentle breezes with quickly passing showers. These terrifying storms were known to have a core of screaming winds accompanied by blinding rain, spume and sea spray, and sharply lowered barometric pressure. When the sailors were lucky enough to survive penetration to the core of such violent weather, they found a region of calm. This region is the signature characteristic and best-known feature of these storms - the eye (Fig. 1).

These violent storms of the tropical latitudes were known to be seasonal, hence their designation by Atlantic sailors as "line" storms, in reference to the sun's crossing of the line (equator) in September (the month of peak hurricane activity in the North Atlantic). Later they became known there as hurricanes, named after Huracan, a Carib god of evil. In the Far East, over the waters of the western North Pacific, hurricanes are known as typhoons. Other local and regional names for these weather systems exist. To meteorologists, hurricanes and typhoons are recognized as a subset of the generic atmospheric phenomenon known as the tropical cyclone (TC). "Cyclone" refers to the direction of rotation of the wind around low-pressure areas-counterclockwise in the Northern Hemisphere, and clockwise in the Southern Hemisphere.

Tropical cyclones are relatively rare with a global annual average of $\approx 85$, and a range of 66 to 105 (Gray, 1979; Lander and Guard, 1998). On any given day there may be no TCs on earth (such is the case for $\approx 100 \mathrm{~d}$ per year), or there may be upwards of five or six. Although there are relatively few TCs on the earth throughout the year, or at any given time, there are always many tropical disturbances; of which a small fraction become TCs. A tropical disturbance is a discrete area of heavy showers and thunderstorms in the tropics or subtropics that is persistent, migratory, and nonfrontal (i.e., it possesses no warm fronts or cold fronts such as those which accompany the extratropical cyclones of the mid-latitudes). Relatively few of these tropical disturbances strengthen enough to be classified as a tropical depression. A tropical depression is an area of lowered sea-level atmospheric pressure accompanied by a cyclonically rotating vortex in the low-level windfield.

Received for publication 26 May 2000. Accepted for publication 20 June 2000. The author, a tropical meteorologist, was asked by Thomas Marler to give a general overview of tropical cyclone structure, physics, and climate for this workshop. This paper in its final form is an outgrowth of that request, and the many discussions that ensued. The cost of publishing this paper was defrayed in part by the payment of page charges. Under postal regulations, this paper therefore must be hereby marked advertisement solely to indicate this fact. ${ }^{1}$ E-mail address: mlander@uog9.uog.edu
Every year, TCs claim many lives-occasionally exceeding 100,000 . Some of the world's greatest natural disasters have been associated with TCs. For example, Tropical Cyclone 02B was the deadliest and most destructive natural disaster on earth in 1991. The associated extreme storm surge along the coast of Bangladesh was the primary reason for the loss of 138,000 lives (Joint Typhoon Warning Center, 1991). It occurred 19 years after the loss of $\approx 300,000$ lives in Bangladesh by a similar TC striking the low-lying Ganges River region in April 1970. In a more recent example, flooding caused by Hurricane Mitch killed 10,000+ people in Central America in Fall 1998. Nearly all tropical islands - the islands of the Caribbean, Hawaii, French Polynesia, Micronesia, Fiji, Samoa, Mauritius, La Reunion, Madagascar, and many others - are vulnerable to direct strikes by intense TCs. Devastating TCs often make landfall in Japan, India,

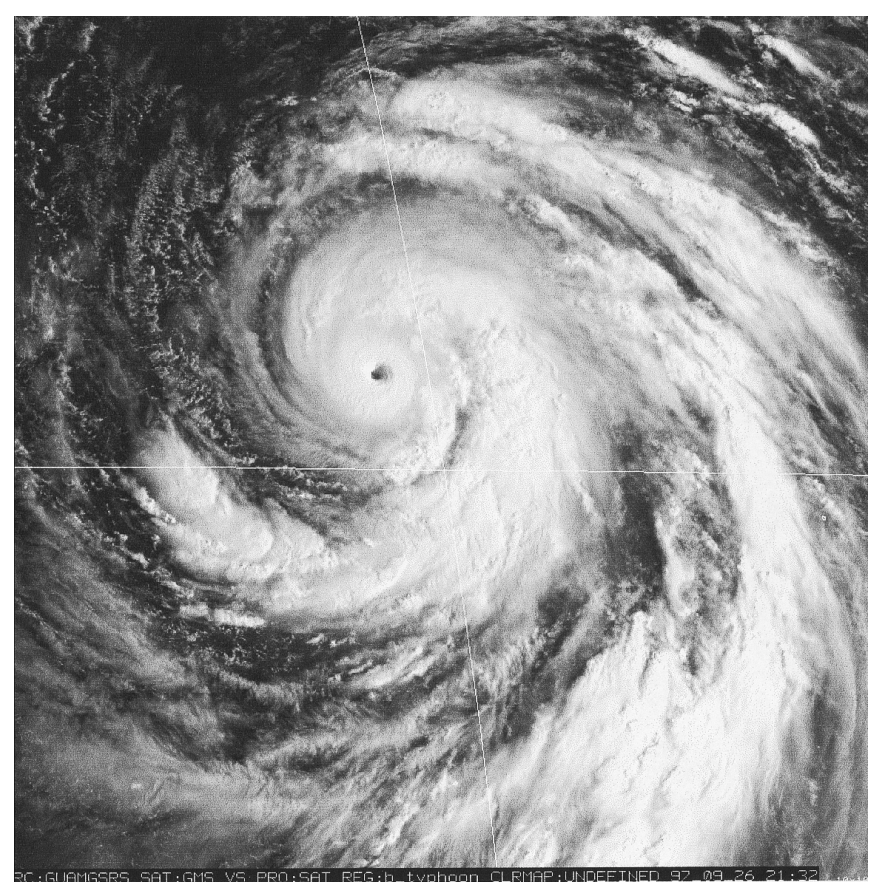

Fig. 1. Possessing a small, well-defined eye and an extensive amount of peripheral rainbands, Ginger becomes a super typhoon far at sea in the western North Pacific Ocean (2132 UTC 26 Sept. 1997 high-resolution visible imagery from the Japanese Geostationary Meteorological Satellite). 
China, Vietnam, the Philippines, the United States, Mexico, and other nations. With their natural tendency to move out of the tropics, TCs (in their later stage of extratropical transition) are also a tangible threat to higher latitude regions such as New England and the Maritime Provinces of Canada.

This paper provides a brief description of the structure, physics and motion of TCs. This is followed by an overview of the hazards associated with TCs and a discussion of some of the proposed changes to TC climate as a result of an anticipated greenhouse gas-induced rise in air and sea-surface temperatures.

Note that tropical cyclone advisories, TC empirical relationships, and TC wind-damage scales are still widely based on units of millibars $\mathrm{mb}$ ) for pressure, nautical miles (n mi) for distance, and knots (kt) for the wind speed. Wherever these units appear in the text, the equivalent measurement in SI units is given in parentheses. $1 \mathrm{mb}=1 \mathrm{hPa} ; 1 \mathrm{n} \mathrm{mi}$ $=1.85 \mathrm{~km}$; and, $1 \mathrm{kt}=0.5144 \mathrm{~m} \cdot \mathrm{s}^{-1}$.

\section{TROPICAL CYCLONE STRUCTURE}

Tropical cyclone structure includes the wind-, thermal- and moisture-fields, the characteristic banded distribution of cloud and rainfall, and the central calm or eye. Three common measures of TC wind-field include intensity, strength and size.

The intensity of a TC is defined as the maximum sustained wind speed near the low-level circulation center. The minimum sea-level pressure within the eye has also been used as a measure of intensity. The maximum wind and minimum sea-level pressure of TCs are loosely related, and TC wind-pressure relationships are often used when the measure of one parameter (usually the maximum sustained wind) is uncertain. A TC wind-pressure relationship developed by Atkinson and Holliday (1977) is used operationally in the western North Pacific. This wind-pressure relationship was especially useful in the days of aircraft reconnaissance, when the central sea-level pressure of the TC was estimated by techniques considered far more reliable than those used to estimate the maximum surface-wind speed.

In official advisories and warnings issued to the public, the winds given for a TC are the expected sustained wind and peak gust. A sustained wind is the highest value of the wind speed averaged over a specific time interval. In the United States, the averaging interval used to derive the sustained wind is $1 \mathrm{~min}$. In other countries, an averaging interval of $10 \mathrm{~min}$ is usually used to derive the sustained wind.

The peak gust is another common parameter used to describe the wind in TCs. When a 1-min averaging interval is used to derive the maximum sustained wind, the peak gust over-water is $\approx 122 \%$ higher than the maximum sustained wind (Krayer and Marshall, 1992). Over land, the gust factor increases. Over flat open terrain with small trees and shrubs, the ratio of the peak gust to the maximum sustained 1-min wind increases to $\approx 1.5$.

As the maximum wind speed of a TC increases, it changes from tropical depression to tropical storm to hurricane/typhoon. By U.S. standards (Office of the Federal Coordinator for Meteorology, 1999), a tropical depression is any TC possessing maximum-sustained overwater winds of $33 \mathrm{kt}\left(17 \mathrm{~m} \cdot \mathrm{s}^{-1}\right)$ or less. A reference height of $10 \mathrm{~m}$ is used for these measurements. A TC becomes a tropical storm when its wind increases to $34-63 \mathrm{kt}\left(18-32 \mathrm{~m} \cdot \mathrm{s}^{-1}\right)$, a hurricane or typhoon when the sustained wind speed increases to $64 \mathrm{kt}\left(33 \mathrm{~m} \cdot \mathrm{s}^{-1}\right)$ or more. In the western North Pacific, a typhoon becomes a super typhoon when the wind surpasses $128 \mathrm{kt}\left(66 \mathrm{~m} \cdot \mathrm{s}^{-1}\right)$. Outside the United States there are other classifications of TCs based on wind speed. For example, "severe tropical storm" is a common classification for TCs possessing maximum sustained winds of 48-63 kt $\left(25-32 \mathrm{~m} \cdot \mathrm{s}^{-1}\right)$.

The strength of a TC is a measure of the winds in an annulus from $1^{\circ}$ to $3^{\circ}$ of great-circle arc $(111-333 \mathrm{~km})$ from the center. Coupled with the intensity, it gives a rough measure of the rate of decrease of the wind beyond the radius of maximum wind. Two TCs may have the same intensity, but possess different strengths. The height of the sea and swell generated by a TC is affected by the strength.

The size of a TC is a difficult parameter to specify and measure. One commonly used measure of TC size is the average distance outward from the center to some specified wind-speed threshold (e.g., $15 \mathrm{~m} \cdot \mathrm{s}^{-1}$ ). Other measures of TC size include the average distance from the center outward to the outermost closed contour of the lowered sealevel pressure associated with the TC. Size is highly variable among TCs. Some typhoons are so small that they have been called "midgets," a name loosely translated from the Japanese "mame taifu," literally, "bean" typhoon (Arakawa, 1952). The entire cloud system of these typhoons may fit into an area $<200 \mathrm{~km}$ in diameter, and gales may extend only $20 \mathrm{~km}$ from the center. At the opposite extreme of size distribution are the giants. For example, Super Typhoon Tip [Joint Typhoon Warning Center (JTWC), 1979] produced gales extending outward for nearly $1000 \mathrm{~km}$ in all directions.

The well-defined eye of a mature TC is probably one of Nature's most remarkable and awe-inspiring phenomena. It is a light-wind core composed in the vertical of gently subsiding warm dry air (hence the lack of clouds there), and is typically surrounded by a more or less complete ring of vertically deep convective clouds termed the "eyewall." In the eyewall, the inward-spiraling air of the TC converges at low levels, and is carried aloft, where most of it then diverges and flows outward-the basic in-up-and-out of the TC vertical circulation. Maximum surface-winds are generally found along the inside edge of the radar-observed eyewall.

The eye of a TC can be ragged or well-defined. In general, the more sharply defined the eye of a TC becomes on meteorological satellite (METSAT) imagery, the more intense that TC is likely to be. The average METSAT-observed diameter of the eye of a TC is between 30 and $45 \mathrm{n} \mathrm{mi} \mathrm{(55-85} \mathrm{km)} \mathrm{(Weatherford,} \mathrm{1984).} \mathrm{Eyes} \mathrm{with} \mathrm{diameters}<30$ $\mathrm{n} \mathrm{mi}(<55 \mathrm{~km})$ are considered to be small, while those with diameters $>45 \mathrm{n} \mathrm{mi}(>85 \mathrm{~km})$ are considered to be large. On weather radar and as experienced from the ground, eye diameters are usually smaller than the METSAT-observed eye diameter as a result of the outward slope of the eyewall cloud with height. As measured by the area of relatively light wind at the surface, TC eye diameters range from $5 \mathrm{~km}$ to over 100 $\mathrm{km}$. In a survey of past annual tropical cyclone reports published by the JTWC, Guam, the largest eye diameter ever reported was that of Typhoon Carmen (JTWC, 1960) as it passed over Okinawa. Carmen's eye diameter, as measured by the weather radar at Kadena Air Base, Okinawa, was $200 \mathrm{n} \mathrm{mi} \mathrm{(370} \mathrm{km).}$

Certain TCs, especially the more intense, develop two eyewalls that are concentric and separated by a relatively cloud-free moat. In such cases, the outer eyewall typically contracts while the inner eyewall collapses in a process known as eyewall replacement. The phenomenon of eyewall replacement has been discussed at length by Willoughby et al. (1982) and Willoughby (1990). These authors note that TC eyes almost invariably contract during intensification so that small eyes and extreme intensity tend to be correlated. The most intense TC ever observed-Super Typhoon Tip-had an intensity of $165 \mathrm{kt}\left(85 \mathrm{~m} \cdot \mathrm{s}^{-1}\right)$, a minimum sea level pressure of $870 \mathrm{hPa}$, and an eye diameter of $12 \mathrm{n} \mathrm{mi}(22 \mathrm{~km})$ when observed by a U.S. Air Force weather reconnaissance aircraft on 11 Oct. 1979 (JTWC, 1979).

\section{TROPICAL CYCLONE PHYSICS}

Although tropical disturbances and tropical depressions can form over land, TCs intensify to hurricanes and typhoons only over the ocean, and usually weaken rapidly upon landfall. This fundamental property of TC distribution hints at the mechanisms governing their development. Friction is an obvious factor acting to oppose the spinup of an intense atmospheric vortex, and is obviously greater over land than over water. But what initiates the spin-up in the first place? What energy reservoir is tapped for conversion to the kinetic energy of the TC wind-field?

Despite decades of scientific research, many aspects of TCs remain enigmatic, and controversy about their physics persists. Early theories proposed that cumulus clouds organized in clumps, rather than randomly spaced, could act to tap the potential energy reservoir existing between the lower and upper levels of the tropical atmosphere. Tropical cyclones were widely believed to be caused by the release of the latent heat of condensation of water vapor in cumulus clouds. Studies of the energetics of hurricanes indicated that something more was needed. The energy source for typhoons and hurricanes is now thought to reside in the thermodynamic disequilibrium between the 
atmosphere and the underlying ocean (Emanuel, 1988). This is reflected in the fact that air immediately above the ocean is subsaturated, yielding a potential for transfer of latent and sensible heat from sea to air, even though the temperatures of the two media are usually about equal. The mature TC can be regarded as an elegant example of a natural Carnot heat engine (an idealized, reversible thermodynamic cycle that converts heat to mechanical energy).

The ability of a TC to extract energy from the sea is enabled by its lowered sea-level pressure and high surface wind. How then does a TC form if it depends on its own existence to enable the air-sea energy exchanges? The formation, or genesis, of TCs is one of the most poorly understood portion of their life cycle. By examining the climatology of TC genesis in relation to large-scale variables, some of the important physical characteristics associated with their formation can be inferred. The most extensive climatology of TC genesis was performed by Gray (1979), who found that the climatological frequency of TC formation was related to six factors: a) above-average low-level vorticity (a measure of the local spin of the air); b) above-average moisture in the middle levels of the atmosphere (1500-6000 m); c) conditional instability through a deep layer (i.e., free ascent of the air would occur if its water vapor began to condense); d) a warm and deep oceanic mixed layer; e) weak vertical shear of the horizontal wind; and, f) a location at least a few degrees poleward of the equator (i.e., a sufficient value of planetary vorticity). The intrinsic spin of the earth's surface with respect to the local vertical governs the sense of rotation of the wind in a TC. This is counterclockwise in the Northern Hemisphere, zero on the equator, and clockwise in the Southern Hemisphere.

These general climatological conditions exist over many regions of the tropics for extended periods of time, and yet TCs rarely form. Gray (1975) hypothesized that TCs would form only when these conditions were perturbed and reached values above their normal climatological range. Attempts to apply these criteria to daily forecasting of TC genesis have had little success. Forecasters have long recognized that a required precursor to TC formation is a preexisting tropical disturbance containing abundant deep convection (i.e., large cumulonimbus clouds of great vertical depth) (e.g., McBride and Gray, 1980; McBride and Zehr, 1981). So, in addition to the special atmospheric conditions that are conducive to them, TCs clearly derive from the influence of these conditions on preexisting tropical disturbances. At any given time, however, there are many tropical disturbances, and the reasons why a select few become TCs is still largely unknown. To date, there has been little progress in the ability to predict TC formation or of changes to the intensity of existing TCs. Substantial departures of TC intensity change from average rates, such as rapid deepening (Holliday and Thompson, 1979) and explosive deepening (Dunnavan, 1981) are rarely successfully anticipated.

\section{TROPICAL CYCLONE MOTION}

To a first order, TCs originate in the tropics and track westward to terminate over land within the tropics, or they move into higher latitudes on roughly "C"- or " $<$ "-shaped tracks, where they die over land or open ocean. A TC moving westward in the tropics that slows, turns poleward, and lastly accelerates as it moves eastward in the midlatitudes is said to have "recurved." While some actual TCs travel on smooth tracks, most tend to meander about a mean path in a more or less complex combination of loops, stalls, abrupt turns, and other prominent excursions (Holland and Lander, 1993) (Fig. 2).

As a crude approximation, TC motion may be conceptualized as the drift of a cork in a stream. In this framework, the TC is simply carried along by the earth's large-scale wind systems (e.g., the tradewind easterlies, the subtropical anticyclones, and the mid-latitude westerlies). Consider a typical North Atlantic hurricane. Born near the African coast, it drifts westward in the tropical easterlies for several days. When it reaches the western side of the basin, it begins a turn to the north as it rides around the periphery of the large clockwise flow of the subtropical high that is often centered near Bermuda. When the hurricane reaches the mid-latitudes, say east of Cape Hatteras, it enters the mid-latitude westerlies and-as it dies-races back across the Atlantic towards Europe. All along its journey, it has roughly followed the course of the large-scale wind patterns, like a cork in a stream.

Real TC motion, however, is more complicated than the analogy of a cork passively following the exact path dictated by the runs and eddies of a stream. Tropical cyclones are not passive atmospheric entities. They can alter the large-scale currents that steer them-an ideal case of the tail wagging the dog. For example, the common trait of most TCs to gain latitude can be partly attributed to the effects of the TC itself operating on its environment. To illustrate this, consider a symmetrical TC embedded in an environment with zero initial flow. Despite the initial absence of a steering current, the TC nevertheless would begin to drift westward and poleward as it induces large-scale flow patterns in the environment (Chan and Williams, 1987; Holland, 1983). The meridional gradient of the intrinsic spin of the earth along a local vertical axis is an essential factor for this self-induced drift of a TC. The path taken by a TC is the final product of the large-scale flow, alterations to the large-scale flow induced by the TC, and interactions of the TC with other weather systems in its environment, such as other TCs, monsoon surges, and mid-latitude highs and lows (Carr and Elsberry, 1994a, 1994b).

Forecasts of TC motion have steadily improved over the past three decades. Official forecasts and guidance from numerical models show substantial improvements over standard benchmark measures of skill such as CLIPER (a simple statistical forecast based on CLImatology and PERsistence). Typical forecast position errors of official TC advisories and numerical guidance are on the order of 150,300 , and $450 \mathrm{~km}$ at 24, 48, and $72 \mathrm{~h}$, respectively (e.g., JTWC, 1996; United Kingdom Meteorological Office, 1999). Studies of intrinsic limits on forecasts of TC motion (e.g., Leslie and Abbey, personal communication) indicate that there is yet room for improvement. Future improvements, however, are likely to be incremental. As it now stands, the accuracy of TC motion forecasts is, on the whole, a success story.

\section{TROPICAL CYCLONE HAZARDS}

There are several hazards associated with TCs. Three primary hazards affect a substantial portion of any populated area, and can cause widespread and immediate damage. These are destructive winds, storm surge and high waves, and flooding. There are additional hazards that are dangerous and costly, but they generally are of less concern or affect fewer people. Emergency managers should have a good understanding of the hazards associated with TCs and understand their potential impacts. The primary and additional hazards include: a) destructive winds and windblown debris; b) storm surge, high surf, and inundation; c) torrential rains and flooding; d) wind shear and mechanical turbulence; e) phenomenal seas; e) tornadoes; f) sea salt deposition; g) erosion and pollution; and h) slope failures.

Public TC advisories typically focus on the intensity of the TC, and secondarily on the expected storm surge, heavy rain, and possibility of embedded tornadoes. Most people have difficulty relating an advertised TC intensity - a numerical value - to its potential for causing damage. Numerous questions come to mind. For example: What kind of specific damage would a $100-\mathrm{kt}\left(51-\mathrm{m} \cdot \mathrm{s}^{-1}\right)$ hurricane cause? What kind of wave action would a $130-\mathrm{kt}\left(67-\mathrm{m} \cdot \mathrm{s}^{-1}\right)$ hurricane produce in a bay or across a reef? At what wind speed would a tin roof blow off? At what wind speed would a car overturn? At what wind speed would concrete power poles sustain damage or blow down? At what wind speed would a significant fraction of mature healthy deciduous trees be uprooted? For the Atlantic and Gulf Coast regions of the United States the Saffir-Simpson Hurricane Scale (SSHS) (Saffir, 1972, 1975; Simpson, 1974) is widely used to relate hurricane wind speed to potential damage. In these regions, the SSHS has taken on the importance for hurricanes that the Richter Scale has taken on for earthquakes in earthquake-prone areas. The innovative SSHS, which ranks hurricanes in categories of destructive potential from Category 1 (weak hurricane) through Category 5 (devastating hurricane), was devised in 1971 by Mr. Herb Saffir, a Miami, Fla.,-based engineer, who developed the scale for the United Nations. He later gave the scale to the National Hurricane Center (NHC) in Miami. Dr. Robert Simpson, then the director of the NHC, added storm surge information to the SSHS. While the SSHS has been used very successfully in the United States, 


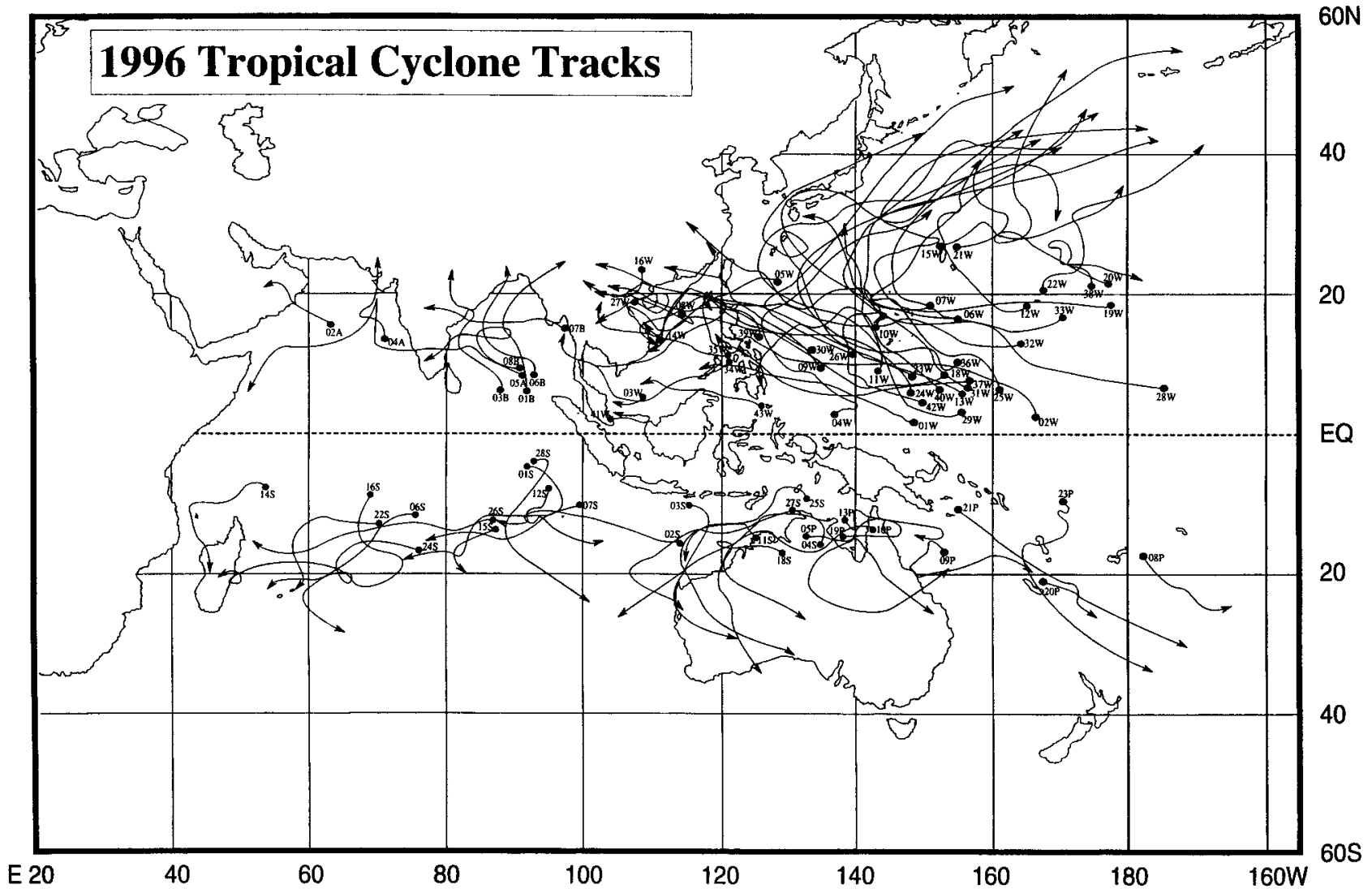

Fig. 2. Tropical cyclone tracks in the eastern hemisphere in 1996.

it has not been applicable to the tropical Pacific (Office of the Federal Coordinator for Meteorology, 1995; Saffir, 1993).

A scale relating TC wind speed to potential damage for the tropical Pacific Ocean region was developed by Guard and Lander (1999). After assessing many available wind-damage scales (e.g., Amadore, 1982; Fujita, 1971), Guard and Lander (1999) adapted the parameters of the SSHS for use in tropical island environments. This new TC wind-damage scale has been coined the Saffir-Simpson Tropical Cyclone Scale (STCS) as recommended by Mr. Herbert Saffir. This STCS ("sticks") scale is specifically adapted for the tropics, and considers the construction and building practices that are common there. It incorporates the harshness of the tropical environment by considering the weakening effects of termite infestation, wood rot, and the corrosion due to salt water inundation and airborne sea-salt. It also identifies the wind and sea-salt damage to tropical trees. Finally, STCS accounts for the unique effects of coral reefs on coastal wave action, storm surge, and wave setup.

Trees are excellent indicators of TC wind speed. Guard and Lander (1999) divide tropical trees into 12 specific types based on their characteristic responses to strong winds. These types were based to a large extent on other studies describing TC damage to tropical trees (e.g., Cameron et al., 1983; Raulerson and Rinehart, 1991). The following is excerpted from Guard and Lander (1999) for Type 1 and Type 8 trees:

"(Type 1) - Palm trees_-Plants with tall woody trunks and a crown of radiating (palm) fronds. Palm fronds begin to crimp, often back through the crown, when winds reach $65 \mathrm{kt}\left[33 \mathrm{~m} \cdot \mathrm{s}^{-1}\right.$ ] (weak TY CAT 1) intensity; crowns begin to break from the top of the trunk (decapitate) when winds reach $100 \mathrm{kt}\left[51 \mathrm{~m} \cdot \mathrm{s}^{-1}\right.$ ] (weak-medium TY CAT 3); falls are around $10 \%$ when wind speeds reach around $105 \mathrm{kt}\left[54 \mathrm{~m} \cdot \mathrm{s}^{-}\right.$ ${ }^{1}$ ]. Coconut palm [Cocos nucifera L.] trunks can also snap at these wind speeds, but falling is more common."

"(Type 8)—Plumeria/Acacia/Albizia/African Tulip/Yoga/Ifil/Orchid/Coral/Cebera/Talisai-Small to large trees that readily shed limbs but generally resist defoliation in strong winds. Trees that survive TY CAT 3 or stronger winds tend to shed large branches and develop stocky, typhoon resistant trunks . . . Despite damage, these trees tend to recover rapidly."

Some of the tree types described by Guard and Lander may share the same characteristics of adjacent types. This is especially the case with Type 8 trees. For example, the African tulip tree (Spathodea campanulata Pal.) has some characteristics of Type 9 trees (heavy defoliation) and the Yoga tree (Elaeocarpus joga E.D. Merrill.) has some characteristics of both a Type 7 tree (strong trunk) and a Type 6 tree (resistance to uprooting).

The primary use of STCS is straightforward. When a TC is threatening a specific tropical location, and warnings are issued reflecting the expected intensity, decision-makers can match the intensity to the appropriate TC Category to determine the potential wind damage and coastal wave action. In practice, disaster management officials frequently prepare a population for the destructive effects of winds one-half to one category higher than those predicted. This is to help compensate for TC intensity prediction errors that can, at times, be large.

Another use of STCS is poststorm assessment of TC intensity from observed damage to structures, infrastructure, and trees, and from observed coastal wave action. This type of analysis is difficult; an accurate assessment requires considerable experience.

\section{TROPICAL CYCLONES AND CLIMATE CHANGE}

Among the more problematic consequences of climate change is the possible change in the distribution and severity of TCs. The issue of TCs and climate change was the subject of an international symposium in Mexico in 1993, organized by J. Lighthill and reported on by Lighthill et al. (1994). An updated assessment of this issue is found in Henderson-Sellers et al. (1998). The following alterations to the present-day distribution and severity of TCs as a product of anticipated greenhouse gas-induced warming are cited in Lighthill et al. (1994): 1) an increase in the global annual number of TCs; 2) an increase in the number of intense TCs; 3 ) an increase in the maximum possible intensity attainable by TCs; 4 ) an increase in the range where TCs may 
form; and 5) an increase in the range where TCs retain their intensity and mature structure. Hypotheses of systematic changes to the global distribution of TCs can be addressed through investigation of the historical record, consideration of changes to the mechanisms now thought to influence TC distribution and structure, and analyses of the output of general circulation model (GCM) simulations.

The very limited record makes extensive analysis of the natural variability of global TC activities difficult in most of the TC basins. However, in the two regions where reasonably reliable records exist (the North Atlantic and the western North Pacific), substantial multidecadal variability (particularly for intense Atlantic hurricanes) is found, but no clear evidence of long-term trends. The realism and hence predictive skill of GCM simulations is greatly limited by the coarse resolution of current GCMs and the failure to capture environmental factors that govern TC intensity. Based on these lines of reasoning, Lighthill et al. (1994) and Henderson-Sellers et al. (1998) concluded that greenhouse gas-induced warming probably will not significantly affect the distribution and severity of TCs, and that at least for the next 60-70 years any effects will be quite small compared with natural variability. The broad geographic regions of TC formation, and, therefore, also the regions affected by TCs, are not expected to change significantly. However, regional and local frequencies could change substantially in either direction, because of the dependence of TC formation and track on other phenomena (e.g., ENSO) that are not yet predictable. Theoretical studies of TC maximum potential intensity indicate that it will remain the same or undergo a modest increase of up to $10 \%$ to $20 \%$. These predicted changes are small compared with the observed natural variations. Greatly improved skills from coupled global ocean-atmosphere models are required before improved predictions are possible.

Although the consensus reported in Lighthill et al. (1994) and Henderson-Sellers et al. (1998) was that possible changes to TC climate (list items 1-5 above) would probably be small compared with natural variability (which itself is poorly understood), one of the coauthors of these two papers warned that predictions of an increase in TC maximum potential intensity (list item 3) need to be taken seriously (Emanuel, 1995). He concluded that increased thermodynamic disequilibrium between the tropical atmosphere and ocean (as is suggested by the current generation of climate models) would probably be accompanied by an increase in the limiting intensity of actual TCs. Several decades may be required before any sustained change to TC climate can be recognized and its cause determined.

\section{CONCLUDING REMARKS}

Each year, tropical cyclones and their many associated hazards cause much loss of life and enormous damage to property and natural resources. Some of the world's greatest natural disasters have been associated with TCs. Forming in every tropical ocean basin, except the South Atlantic, TCs are a threat to much of the earth's population. With more and more people residing and building on tropical islands and TC-prone coastlines of many nations, there is ever more at risk to TC hazards. Disaster preparation and mitigation efforts must evolve to meet the increasing challenges-witness the largest mass evacuation in American history when more than 1 million people were evacuated from the east coast of Florida at the approach of the powerful Hurricane Floyd. Strategies for recovery after a TC must also be tailored to meet the growing risks and cascade of problems that may arise-witness the devastating floods in North Carolina caused by Hurricane Floyd, and the unanticipated health risks associated with the drowning of thousands of pigs, chickens, and other farm animals.

Like the human effort to withstand and recover from the TC disaster, the natural world appears to employ certain strategies to withstand and recover from TCs. These strategies vary among areas affected by TCs, and have differing degrees of success. A wind that would fell nearly every tree in the forests of New England would only fell a small fraction of a stand of coconut palms in a TC-prone location in the deep tropics. On my home island of Guam, two typhoons (Elsie and Hunt) passed near, and three (Omar, Brian, and Gay) passed directly over the island during 1992 . Wind gusts to $130 \mathrm{kt}\left(67 \mathrm{~m} \cdot \mathrm{s}^{-1}\right)$ in Typhoon Omar, and a mist of airborne sea salt in Typhoon Gay caused great destruction of the island's vegetation. A major drought in 1993 followed this onslaught of TCs. Five years later, during Dec. 1997, an even more intense typhoon (Paka) raked the island with wind gusts reliably measured to $149 \mathrm{kt}\left(77 \mathrm{~m} \cdot \mathrm{s}^{-1}\right)$. The damage to residential and commercial infrastructure and to the island's vegetation was extensive. After Paka in 1997, severe drought conditions ensued in 1998 , and 1400 individual wildfires scorched $12 \%$ of the land area of the island. Now, 2 years later, the island has recovered remarkably well. One can stand in the cool shade of coconut groves along coralsand beaches, watch small waves breaking along the reef margin, and wonder what the fuss over typhoons is all about.

\section{Literature Cited}

Amadore, L.A. 1982. Preliminary typhoon damage scale in the Philippines, Manila, Republic of The Philippines. Minutes of a Joint Session of the Amer. Meteorol. Soc. and the Philippine Atmos. Geophys. and Astronomical Serv. Admin. (PAGASA).

Arakawa, H. 1952. Mame Taifu or midget typhoon (small storms of typhoon intensity). Geophys. Mag. 23:463-474.

Atkinson, G.D. and C.R. Holliday. 1977. Tropical cyclone minimum sea-level pressure and maximum sustained wind relationship for the western North Pacific. Monthly Weather Rev. 105:421-427.

Cameron, D.M., S.J. Rance, and P.J. Lukitsch. 1983. Tree damage in Darwin parks and gardens during cyclones Tracy and Max. Landscape Planning 10:89-108.

Carr, L.E. and R.L. Elsberry. 1994a. Systematic and integrated approach to tropical cyclone track forecasting, Part I: Description of basic approach. Naval Postgraduate School publication NPS-MR-002. Naval Postgraduate School, Monterrey, Calif.

Carr, L.E. and R.L. Elsberry. 1994b. Monsoonal interactions leading to sudden tropical cyclone track changes. Monthly Weather Rev. 123:265-289.

Chan, J.C.-L. and R.T Williams. 1987. Analytical and numerical studies of the beta-effect in tropical cyclone motion. Part I. Zero mean flow. J. Atmos. Sci. 44:1257-1264.

Dunnavan, G.M. 1981. Forecasting intense tropical cyclones using 700-mb equivalent potential temperature and sea-level pressure. Naval Oceanography Command Ctr./Joint Typhoon Warning Ctr. Tech. Note 81-1.

Emanuel, K.A. 1988. Toward a general theory of hurricanes. Amer. Sci 76:370-379.

Emanuel, K.A. 1995. Comments on "Global Climate Change and Tropical Cyclones": Part I. Bul. Amer. Meteorol. Soc. 76:2241-2243.

Fujita, T.T. 1971. Proposed characterization of tornadoes and hurricanes by area and intensity. Satellite and Mesometeorology Res. Project, Res. Paper 91, Univ. of Chicago, Ill.

Gray, W.M. 1975. Tropical cyclone genesis. Colorado State Univ. Dept. of Atmos. Sci. Paper No. 232. Colorado State Univ., Fort Collins.

Gray, W.M.. 1979. Hurricanes: Their formation, structure and likely role in the tropical circulation, p. 155-218. In: D.B. Shaw (ed.). Meteorology over the tropical oceans. Royal Meteorol. Soc., Berkshire, U.K.

Guard, C.P. and M.A. Lander. 1999. A scale relating tropical cyclone wind speed to potential damage for the tropical Pacific Ocean region: A user's manual. Water and Environ. Res. Inst. (WERI) of the western Pacific, Tech. Rpt. 86. WERI, Univ. Guam, Mangilao.

Henderson-Sellers, A., H. Zhang, G. Berz, K. Emanuel, W. Gray, C. Landsea, G. Holland, J. Lighthill, S.-L Sheh, P. Webster, and K. McGuffie, 1998: Tropical cyclones and global climate change: A post-IPCC Assessment, Bul. Amer. Meteorol. Soc. 79:19-38.

Holland, G.J. 1983. Tropical cyclone motion: Environmental interaction plus a beta effect. J. Atmos. Sci. 40:328-342.

Holland, G.J. and M.A. Lander. 1993. The meandering nature of tropical cyclone tracks. J. Atmos. Sci. 50:1254-1266.

Holliday, C.R. and A.H. Thompson. 1979. Climatological characteristics of rapidly intensifying typhoons. Monthly Weather Rev. 107:1022-1034.

Joint Typhoon Warning Center. 1960. Typhoon Carmen. 1960 Annual Typhoon Rpt. [NTIS AD 786147.] Natl. Tech. Infor. Serv. (NTIS), Springfield, Va.

Joint Typhoon Warning Center. 1979. Super Typhoon Tip. 1979 Annual Tropical Cyclone Rpt. [NTIS AD A082071]. Natl. Tech. Infor. Serv. (NTIS), Springfield, Va.

Joint Typhoon Warning Center. 1991. Tropical Cyclone 02B. 1991 Annu. Trop. Cyclone Rpt. [NTIS AD A251952.] Natl. Tech. Infor. Serv. (NTIS), Springfield, Va.

Joint Typhoon Warning Center. 1996. Error statistics. 1996 Annu. Trop. Cyclone Rpt. [NTIS AD A332916] Natl. Tech. Infor. Serv. (NTIS), Springfield, Va.

Krayer, W.R. and R.D. Marshall. 1992. Gust factors applied to hurricane winds. Bul. Amer. Meteorol. Soc. 73:613-617.

Lander, M.A. and C.P. Guard. 1998. A look at global tropical cyclone activity 
during 1995: Contrasting high Atlantic activity with low activity in other basins. Monthly Weather Rev. 126:1163-1173.

Lighthill, J., G. Holland, W. Gray, C. Landsea, G. Craig, J. Evans, Y. Kurihara, and C. Guard. 1994. Global climate change and tropical cyclones. Bul. Amer. Meteorol. Soc. 75:2147-2157.

McBride, J.L. and W.M. Gray. 1980. Mass divergence in tropical weather systems. Paper II: Large scale controls on convection. Quart. J. Royal Meteorol. Soc. 106:517-538.

McBride, J.L. and R. Zehr. 1981. Observational analysis of tropical cyclone formation, Part II: Comparison of non-developing versus developing systems. J. Atmos. Sci. 38:1132-1151.

Office of the Federal Coordinator for Meteorological Services and Supporting Research. 1995. Saffir Simpson Hurricane Scale. Natl. Hurricane Operations Plan, FCM-P12-1995, Appendix E., Federal coordinator of Meteorol. Services and Supporting Res., Dept. of Commerce, Rockville, Md.

Office of the Federal Coordinator for Meteorological Services and Supporting Research. 1999. National Hurricane Operations Plan, U.S. Dept. of Commerce Federal coordinator of Meteorol. Serv. and Supporting Res., Dept. of Commerce, Rockville, Md.

Raulerson, L. and A. Rinehart. 1991. Trees and shrubs of the Northern Mariana Islands. Coastal Resources Mgt., Office of the Governor, Commonwealth of the Northern Mariana Islands, Saipan.
Saffir, H.S. 1972. The nature and extent of structural damage caused by Hurricane Camille, Natl. Oceanic and Atmos. Admin. (NOAA), Washington, D.C.

Saffir, H.S. 1975. Low-cost construction resistant to earthquakes and hurricanes. United Nations, New York.

Saffir, H.S. 1993. Evaluation of structural damage caused by hurricanes. Phase 1, Final Rpt. Natl. Sci. Foundation, Washington, D.C.

Simpson, R.H. 1974. The hurricane disaster potential scale. Weatherwise 27:169-186.

United Kingdom Meteorol. Office. 1999. Direct position errors for all northern hemisphere storms in 1998 season. Monthly Summaries of Tropical Cyclone Activity and Forecasts. Forecasting and Systems Branch, UK Meteorol. Office, Headquarters, Bracknell, England. (http://www.met-office.gov.uk under section "Education and Weather").

Weatherford, C.L. 1984. Typhoon structural variability. Colorado State Univ. Atmos. Sci. Paper 391. Dept. Atmos. Sci., Colorado State Univ., Fort Collins.

Willoughby, H.E. 1990. Temporal changes in the primary circulation in tropical cyclones. J. Atmos. Sci. 47:242-264.

Willoughby, H.E., J.A. Clos, and M.G. Shoreibah. 1982. Concentric eye walls, secondary wind maxima, and the evolution of the hurricane vortex. J. Atmos. Sci. 39:395-411. 